ISSN 0103-5150

Fisioter. Mov., Curitiba, v. 24, n. 3, p. 389-400, jul./set. 2011 Licenciado sob uma Licença Creative Commons

\title{
Confiabilidade inter e intraexaminadores nas mensurações angulares por fotogrametria digital e goniometria
}

\author{
Reliability inter and intra-tester in angular measures by \\ photogrammetry versus goniometry
}

\author{
Jean Douglas Moura dos Santos ${ }^{[a]}$, Marco Antonio de Oliveira ${ }^{[b]}$, Nelson José Freitas da Silveira ${ }^{[c]}$, \\ Sérgio de Souza Carvalho ${ }^{[\mathrm{d}]}$, Adeno Gonçalves Oliveira ${ }^{[\mathrm{e}]}$ \\ [a] Mestrando em Bioengenharia pela Universidade do Vale do Paraíba (UNIVAP), São José dos Campos, SP - Brasil, e-mail: \\ jeanfisiobr@yahoo.com.br \\ [b] Professor Doutor em Biociências e Biotecnologia pela Universidade Estadual do Norte Fluminense - Darcy Ribeiro \\ (UENF), professor do curso de Pós-Graduação em Bioengenharia da Universidade do Vale do Paraíba (UNIVAP), São José \\ dos Campos, SP - Brasil. \\ [c] Professor Doutor em Biofísica Molecular pela Universidade Estadual Paulista - Júlio Mesquita Filho (UNESP), professor \\ do curso de graduação em Biotecnologia da Universidade Federal de Alfenas (UNIFAL), Alfenas, MG - Brasil. \\ [d] Mestre em Bioengenharia pela Universidade do Vale do Paraíba (UNIVAP), São José dos Campos, SP - Brasil. \\ [e] Professor titular da Faculdade de Ciências Saúde e Tecnologia NOVAFAPI, Teresina, PI - Brasil.
}

\section{Resumo}

Introdução: A utilização da fotogrametria computadorizada em prol da goniometria, ou vice-versa, na prática clínica ainda necessita de fundamentações consistentes. Objetivos: Os objetivos deste estudo foram: verificar a confiabilidade inter e intraexaminadores avaliadores na quantificação das medidas angulares obtidas a partir da fotogrametria computadorizada e a goniometria e determinar a confiabilidade paralela entre esses dois diferentes instrumentos de avaliação. Materiais e métodos: 26 voluntários e 4 examinadores foram utilizados no estudo. A coleta foi realizada em 4 etapas sequenciais: demarcação dos pontos anatômicos de referência, mensuração e registro dos valores goniométricos, captação da imagem do voluntário com os marcadores fixados no corpo e avaliação do registro fotográfico no programa ImageJ. Resultados: O goniômetro é um instrumento confiável na maioria das evidências, porém, a confiabilidade das medições depende principalmente da uniformização dos procedimentos. Considerações metodológicas relativas ao estabelecimento de confiabilidade e padronização da colocação dos marcadores se fazem necessárias, 
de modo a oferecer opções de avaliação ainda mais confiáveis para a prática clínica. Conclusão: Ambos os instrumentos são confiáveis e aceitáveis, porém, mais evidências ainda são necessárias para suportar a utilização desses instrumentos, pois poucos pesquisadores têm utilizado o mesmo desenho de estudo, e a comparação dos resultados entre eles muitas vezes são difíceis.

Palavras-chave: Fotogrametria. Artrometria articular. Reprodutibilidade dos testes.

\section{Abstract}

Introduction: The use of photogrammetry in support of goniometry or vice versa in clinical practice still requires consistent reasoning. Objectives: The objectives of this study were to verify the inter and intra-tester reliability evaluators in the quantification of angular measurements obtained from the photogrammetry and goniometry and determine the reliability parallel between these two different assessment tools. Materials and methods: 26 volunteers and 4 examiners were used in the study. Data collection was performed in 04 sequential steps: demarcation of anatomical reference points, measurement and recording of goniometric values, image capture volunteer with the markers attached on the body and evaluation of photographic registration in the program ImageJ. Results: The goniometer is a reliable instrument in most of the evidence, but the reliability of the measurements depends mainly on the standardization of procedures. Methodological considerations regarding the establishment of reliability and standardization of the placement of markers are needed in order to offer options for further evaluation reliable for clinical practice. Conclusion: Both instruments are reliable and acceptable, but still needed more evidence to support their use of these instruments, because few researchers have used the same study design, and comparison of results between them, are often difficult.

Keywords: Photogrammetry. Arthrometry articular. Reproducibility of results.

\section{Introdução}

As ciências e as profissões médicas estão passando por uma mudança de paradigma em direção à prática baseada em evidências (PBE), definida como a integração das melhores evidências disponíveis por meio de pesquisas e experiências clínicas com os valores encontrados nos pacientes $(1,2)$.

A amplitude de movimento (ADM) que uma articulação consegue realizar constitui uma função da morfologia da articulação, da cápsula e dos ligamentos, assim como dos tendões ou músculos que cruzam essa articulação (3).

Avaliar medidas angulares no corpo humano reflete a investigação de disfunção articular, assim como estima a integridade e a flexibilidade dos tecidos moles em atividade na realização de um movimento ou postura estática $(4,5)$.

Para o avaliador, é necessária uma boa compreensão das técnicas de avaliação e dos princípios de aplicação para que se possam obter resultados confiáveis e válidos. Com base nos resultados das mensurações, é possível estabelecer estratégias de ação ergonômica, terapêutica, diagnóstica ou prognóstica (6-8).

Uma simples observação visual é muito subjetiva na análise dos movimentos e as estruturas articulares, assim, tornam-se imprescindíveis para a aplicação de algum método de avaliação. Diversos são os instrumentos utilizados para a verificação da amplitude de movimento, tais como: goniômetro universal $(9,10)$, dinamômetro isocinético (11), flexímetro (12) e fotogrametria computadorizada (13).

A goniometria manual é um método largamente utilizado na prática clínica de médicos, terapeutas ocupacionais, ergonomistas e fisioterapeutas, para a avaliação da amplitude de movimento e postura (12-14). Entre as vantagens da quantificação angular por goniometria, pode-se citar o baixo custo do instrumento e a fácil mensuração, que depende quase que exclusivamente da experiência anterior do avaliador. Essas vantagens tornam a goniometria manual bastante acessível na prática clínica e profissional (15).

A fotogrametria computadorizada fundamenta-se na aplicação do princípio fotogramétrico às imagens 
fotográficas, obtidas de movimentos corporais, sendo um recurso de avaliação não invasivo, que apresenta vantagens na efetividade de sua aplicação clínica. Com o crescente foco sobre a PBE, os estudos realizados para investigar a confiabilidade e utilidade diagnóstica de testes estão se tornando mais comuns (1).

As evidências ainda não são suficientes quanto à confiabilidade e a repetibilidade da mensuração angular com goniômetro. Verifica-se que, para as articulações dos membros superiores e inferiores, a goniometria possui uma confiabilidade considerada de boa a excelente, embora apresente baixa confiabilidade para a mensuração da amplitude de movimento do tronco $(16)$. Alguns autores $(6,17)$ mostraram alta credibilidade da goniometria para medidas de amplitude de movimento do ombro e do joelho, se comparada com os métodos de estimativa visual e radiografia, respectivamente, e confiabilidade moderada da goniometria para dorsiflexão de tornozelo, quando comparada à do inclinômetro digital (14).

Em um estudo (18) com 21 voluntários verificouse que a fotogrametria computadorizada apresentou confiabilidade aceitável inter e intraexaminadores para as medidas angulares da face e do corpo, muito embora a repetibilidade desse método tenha sido baixa. Outro estudo (19) observou alta confiabilidade inter e intraexaminadores com 18 voluntários para todas as medidas angulares realizadas na fotogrametria, encontrando baixa repetibilidade do método. Entretanto, há pesquisas (20) que encontraram tanto confiabilidade quanto repetibilidade adequadas no método em 20 voluntários, avaliados os ombros e a cervical.

Apesar de todos os cuidados metodológicos nos estudos científicos para testar a confiabilidade e a repetibilidade das mensurações angulares, a utilização da fotogrametria computadorizada em prol da goniometria, ou vice-versa, na prática clínica ainda necessita de fundamentações consistentes, uma vez que os resultados das pesquisas que realizaram esses testes são muitas vezes conflitantes.

Sendo assim, os objetivos deste estudo foram:

1) verificar a confiabilidade inter e intraexaminadores na quantificação das medidas angulares obtidas a partir da fotogrametria computadorizada e a goniometria; $\mathrm{e}$

2) determinar a confiabilidade paralela entre esses dois diferentes instrumentos de avaliação.

\section{Casuística}

\section{Sujeitos}

Vinte e seis voluntários (24 mulheres e 02 homens), acadêmicos do curso de Fisioterapia da faculdade NOVAFAPI (Teresina, PI) foram escolhidos por demanda espontânea para a realização deste estudo. A idade média das mulheres foi 22,6 $\pm 2,8$ anos e dos homens, 20 anos. Os voluntários não apresentavam queixas álgicas ou disfunções neurológicas ou musculoesqueléticas.

Quatro examinadores, acadêmicos de fisioterapia, foram recrutados e, antes das avaliações, todos foram treinados quanto às técnicas de anatomia palpatória para localização dos pontos anatômicos de referência e quanto aos métodos de goniometria e avaliação postural angular no software ImageJ.

Todos os estudantes (voluntários e examinadores) receberam informações para a participação no projeto e assinaram o Termo de Consentimento Livre e Esclarecido de acordo com a resolução 196/96 do Conselho Nacional de Saúde, segundo processo CAAE n. 0062.0.043.000-10.

Todos os procedimentos desenvolvidos neste estudo foram planejados, sendo elaborado um projeto, previamente submetido e aprovado pelo Comitê de Ética e Pesquisa da Faculdade de Ciências e Tecnológicas do Piauí (NOVAFAPI).

\section{Procedimentos}

Definido o perfil da amostra, passou-se à coleta de dados. Essa coleta foi realizada em quatro etapas sequenciais, a saber:

1) demarcação dos pontos anatômicos de referência;

2) mensuração e registro dos valores goniométricos;

3) captação da imagem do voluntário com os marcadores fixados no corpo;

4) avaliação do registro fotográfico no programa ImageJ.

A coleta das imagens foi realizada no Laboratório de Biofotogrametria da Faculdade NOVAFAPI. Para o registro fotográfico, foi utilizada uma câmera fotográfica digital $\left(\mathrm{H}-10\right.$, Sony $\left.{ }^{\circledR}\right)$ com 8.1 megapixels de 
resolução, posicionada paralela ao chão, sobre um tripé nivelado (MK4, VANGUARD). A sala do laboratório era bem iluminada e reservada, permitindo a privacidade do sujeito a ser fotografado. Os voluntários, trajando roupa de ginástica, calção de banho ou sunga foram fotografados no plano sagital e frontal direita.

Ao realizar o registro fotográfico, os voluntários permaneciam em ortostatismo, posicionados em um local previamente marcado, com uma distância padrão da máquina fotográfica - $3 \mathrm{~m}$. A altura da máquina no tripé foi de $1 \mathrm{~m}$ do chão para fotografar o corpo inteiro (Figura 1).

A demarcação dos pontos anatômicos foi realizada no lado direito do corpo e serviu para traçar os ângulos avaliados. Essas marcações foram feitas com etiquetas autoadesivas (Pimaco ${ }^{\circledR}$ ) de $13 \mathrm{~mm}$ de diâmetro e bolas de isopor de 5,0 cm de diâmetro; estas foram presas por fita adesiva dupla face sobre o acrômio e trocânter maior do fêmur direito do voluntário. Os pontos anatômicos utilizados neste estudo estão demarcados nas Figuras 2 e 3.

A quantificação angular, tanto pelo método goniométrico quanto pela fotogrametria, foi determinada seguindo os parâmetros indicados conforme o Quadro 1.

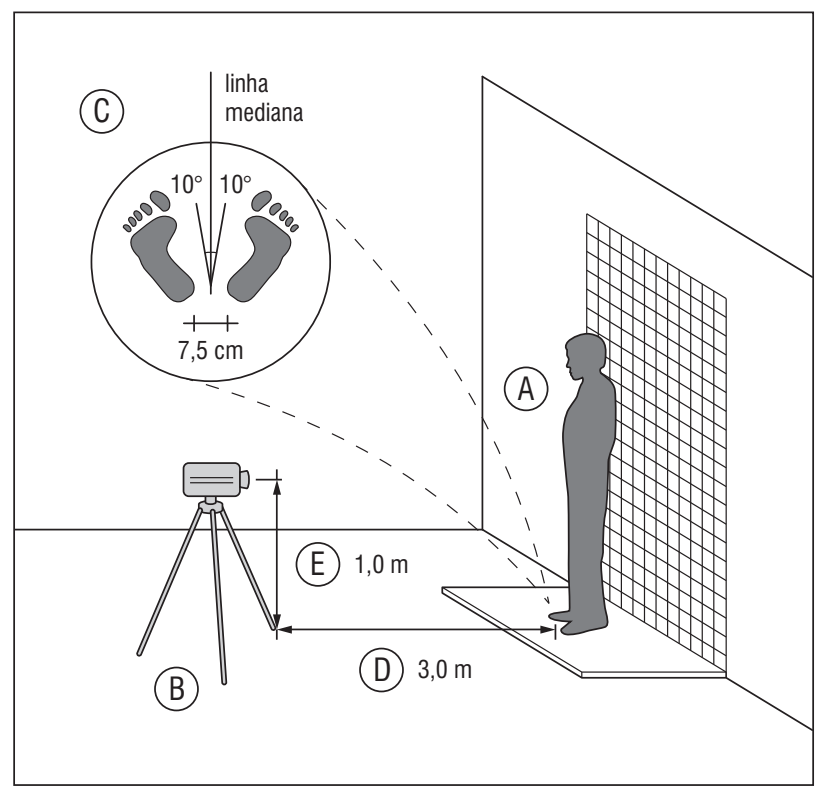

Figura 1 - Posicionamento para a coleta das imagens

Legenda: $\mathrm{A}=$ indivíduo posicionado para a coleta das imagens; $\mathrm{B}=$ câmera fotográfica; $C=$ posição dos pés; $D=$ distância entre a câmera e 0 voluntário; $E$ = distância entre a câmera e 0 solo.

Fonte: Adaptado de Sanches et al., 2008 (21).

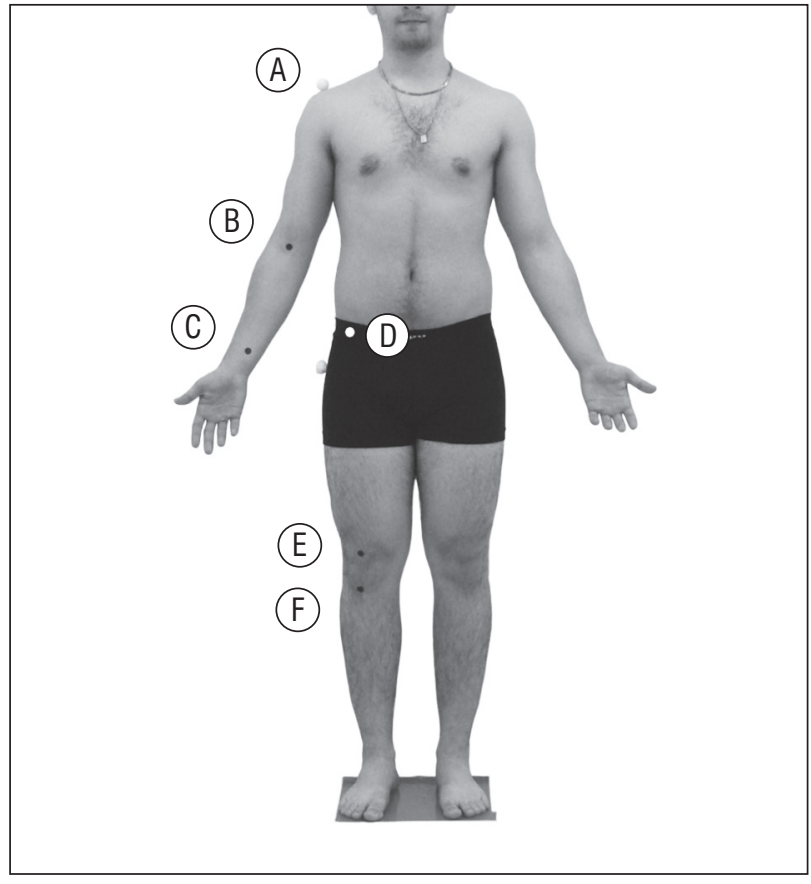

Figura 2 - Marcos anatômicos de referência para mensuração angular em vista anterior

Legenda: Pontos: $A=$ acrômio; $B=$ inserção do tendão do bíceps braquial; $\mathrm{C}=$ ponto médio entre rádio e ulna distal; $\mathrm{D}=$ espinha ilíaca ântero-superior; $\mathrm{E}=$ centro da patela; $\mathrm{F}=$ tuberosidade da tíbia.

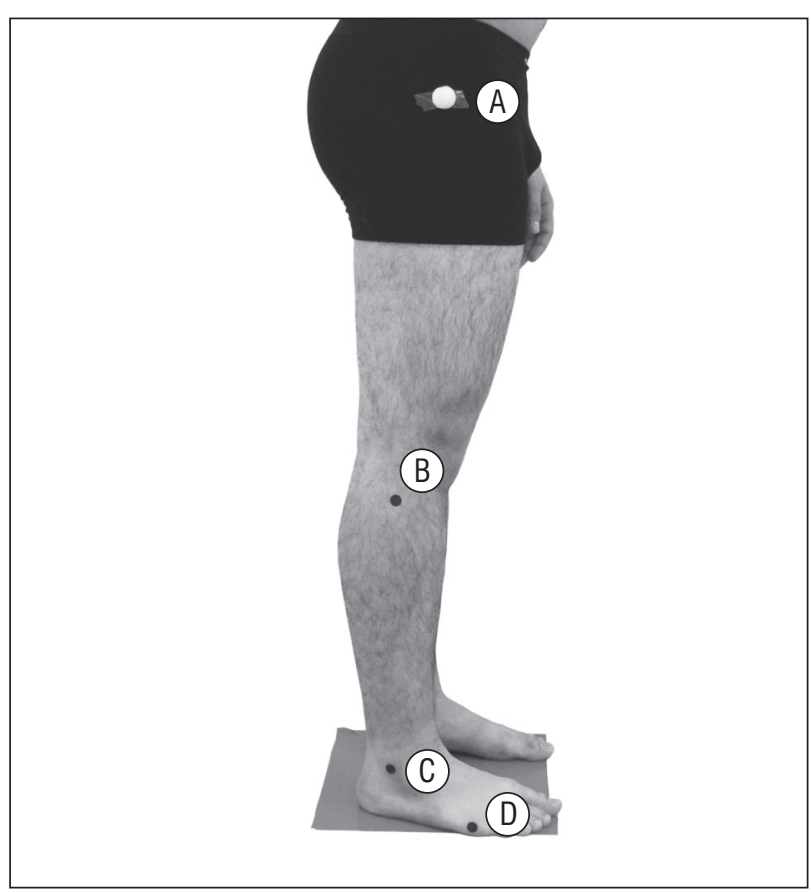

Figura 3 - Marcos anatômicos de referência para mensuração angular em vista lateral

Legenda: Pontos: $\mathrm{A}=$ trocânter maior do fêmur; $\mathrm{B}=$ cabeça da fíbula; $C=$ maléolo lateral do tornozelo; $D=$ cabeça do quinto metatarsiano. 
Quadro 1 - Pontos anatômicos de referência para determinação dos valores angulares

\begin{tabular}{|c|c|c|c|}
\hline Ângulo & Vértice & Semirreta 1 & Semirreta 2 \\
\hline Ângulo tibiotársico (ATT) & Maléolo lateral do tornozelo & $\begin{array}{l}\text { Direcionada à cabeça do } 5^{0} \\
\text { metatarsiano }\end{array}$ & Direcionada à cabeça da fíbula \\
\hline $\begin{array}{l}\text { Ângulo de extensão/flexão de joelho } \\
\text { (AEFJ) }\end{array}$ & Cabeça da fíbula & $\begin{array}{l}\text { Superfície lateral da coxa, } \\
\text { em direção ao trocânter } \\
\text { maior do fêmur }\end{array}$ & $\begin{array}{l}\text { Ao longo da fíbula, em direção } \\
\text { ao maléolo lateral }\end{array}$ \\
\hline Ângulo $Q(A Q)$ & Centro da patela & $\begin{array}{l}\text { Ao longo do fêmur, em } \\
\text { direção à EIAS }\end{array}$ & Tuberosidade tibial \\
\hline Ângulo de carga do cotovelo (ACC) & Inserção do tendão biciptal & Em direção ao acrômio & Ponto médio entre rádio e ulna \\
\hline
\end{tabular}

Fonte: Marques, 2003 (35).

Posterior à marcação dos pontos, cada examinador registrava o valor encontrado na avaliação goniométrica, usando um goniômetro universal de plástico. Em seguida, o voluntário posicionava-se diante da câmera fotográfica, em posição anatômica, para os registros fotográficos serem analisados no programa ImageJ. Os examinadores receberam instruções para utilização da ferramenta digital e determinação dos valores angulares.

\section{Análise da confiabilidade intra e interexaminador}

Para a análise estatística, os dados foram apresentados como média e desvio-padrão da média e foi aplicada a análise de variância (ANOVA oneway), seguido por teste post-hoc (Newman-Keuls) para comparação dos examinadores (confiabilidade interexaminadores). Para comparação das mensurações por fotogrametria computadorizada e goniometria do mesmo examinador (confiabilidade intraexaminadores) foi usado o teste t de Student. 0 nível de significância foi fixado em alfa < 0,05 e IC 95\%.

\section{Resultados e discussão}

Embora o goniômetro seja uma ferramenta comum entre fisioterapeutas, com o avanço da tecnologia vários software têm sido desenvolvidos para determinar se um segmento corporal ou uma articulação desviam-se de um alinhamento postural ideal.

A confiabilidade e a utilidade de testes e medidas devem ser consideradas antes de serem incluídas como componentes do exame clínico. Os testes e medidas devem demonstrar uma confiabilidade adequada antes de serem utilizados para guiar o processo de decisão fisioterapêutica.

No contexto clínico, uma medida não pode ser considerada significativa se não é válida e confiável. Os pacientes podem ser avaliados e reavaliados por diferentes fisioterapeutas ao longo de seu tratamento. Portanto, a confiabilidade da medida é um importante parâmetro para permitir a consistência dos dados ao longo da evolução dos pacientes e nos estudos científicos (14).

Nesse aspecto, com o intuito de verificar o grau de correlação interexaminadores, nos resultados deste estudo pôde-se verificar que não existem diferenças estatisticamente significantes nas avaliações por biofotogrametria nas quatro variáveis estudadas (ângulo de carga do cotovelo, ângulo $Q$, ângulo do joelho e ângulo tibiotársico), não obtendo diferenças estatísticas significantes quando os examinadores usaram o goniômetro como ferramenta de determinação do valor angular (Tabela 1).

\section{Ângulo de carga do cotovelo}

A flexão e a extensão do cotovelo ocorrem sobre um eixo médio-lateral de rotação, passando pelas adjacências do epicôndilo lateral. De medial para lateral, o eixo segue ligeiramente para cima, graças, em parte, ao prolongamento distal da margem medial da tróclea. A assimetria da tróclea faz com que a ulna se desvie lateralmente em relação ao úmero, gerando o que chamamos de ângulo de carga ou ângulo de transporte (22). 
Tabela 1 - Correlação interexaminadores dos valores de média \pm desvio-padrão da média para os parâmetros avaliados das mensurações angulares por biofotogrametria digital e goniometria

\begin{tabular}{lrrrrr}
\hline & Examinador $\mathbf{1}$ & Examinador 2 & Examinador 3 & Examinador 4 & \\
\cline { 2 - 4 } Variáveis & Média \pm SD & Média \pm SD & Média \pm SD & Média \pm SD & P \\
\hline Fotogrametria computadorizada & & & & \\
\hline ACC & $9,5 \pm 4,11$ & $8,77 \pm 4,57$ & $10,0 \pm 5,09$ & $9,46 \pm 4,13$ & 0,8044 \\
AQ & $15,92 \pm 6,17$ & $17,27 \pm 5,89$ & $14,65 \pm 6,25$ & $14,77 \pm 5,28$ & 0,8396 \\
AEFJ & $4,96 \pm 3,08$ & $5,62 \pm 3,54$ & $5,04 \pm 3,54$ & $4,89 \pm 4,51$ & 0,1255 \\
ATT & $29,38 \pm 6,85$ & $28,58 \pm 6,07$ & $27,12 \pm 5,69$ & $27,77 \pm 5,64$ & 0,5660 \\
\hline Goniometria & & & & \\
\hline ACC & $9,77 \pm 3,45$ & $8,62 \pm 2,98$ & $9,73 \pm 2,51$ & $9,46 \pm 4,13$ & 0,5663 \\
AQ & $11,00 \pm 3,32$ & $11,62 \pm 4,38$ & $11,92 \pm 4,11$ & $14,77 \pm 5,28^{\mathrm{a}}$ & $0,0114^{*}$ \\
AEFJ & $2,42 \pm 3,04$ & $5,15 \pm 4,16$ & $2,85 \pm 3,75$ & $4,89 \pm 4,51$ & 0,0233 \\
ATT & $23,77 \pm 4,05^{\mathrm{b}}$ & $18,08 \pm 4,65^{\circ}$ & $28,42 \pm 4,75$ & $27,77 \pm 5,64$ & $<0.0001^{* *}$ \\
\hline
\end{tabular}

Legenda: Média = média aritmética dos valores obtidos; $S D=$ desvio-padrão da média; $A C C=$ ângulo de carga do cotovelo; $A Q=$ ângulo $Q$ do joelho; $A E F J=$ ângulo de extensão/flexão do joelho; ATT = ângulo tibiotársico do tornozelo; * $=p<0,05 ;{ }^{* *}=p<0,001$ para one-way ANOVA; ${ }^{a}=p<0,05$ em relação aos outros examinadores para 0 teste de Newman-Keuls; ${ }^{b}=p<0,01$ em relação aos examinadores 3 e 4 para 0 teste de Newman-Keuls; ${ }^{c}=p<0,001$ em relação aos examinadores 1,3 e 4 para 0 teste de Newman-Keuls.

Esse ângulo é definido como o ângulo entre o eixo anatômico da ulna e o úmero medido no plano ântero-posterior (sagital) em extensão. 0 ângulo é menor em crianças que nos adultos e é maior em mulheres que em homens, alcançando a média de 10-13 graus de angulação valga, respectivamente, com uma ampla distribuição em ambos (23).

Diferentes trabalhos analisaram a confiabilidade inter e intraexaminador nas medidas de arcos de movimento para flexão/extensão (24-26) do cotovelo e supinação e pronação do antebraço $(25,27)$. Contudo, não foram encontrados estudos que estabelecessem a confiabilidade de avaliação do ângulo de carga do cotovelo.

Nesta pesquisa, ao se estabelecer a correlação interexaminador pelo método fotogramétrico e por goniometria (Gráficos 1 e 2), foi possível observar similaridade dos resultados obtidos pelos examinadores entre os dois métodos, ou seja, todos os examinadores utilizaram as ferramentas de avaliação de forma similar (Tabela 1).

É muito provável que existam diferenças na precisão das medidas de goniometria e fotogrametria nas diferentes articulações do corpo. Os erros de medição podem ser influenciados:
1) por diferenças no comprimento do segmento;

2) pela identificação dos marcos ósseos; ou

3) pela posição em que as articulações são avaliadas.

Assim, variações individuais entre os voluntários e os diferentes níveis de habilidade geométrica entre os examinadores exigem que os dados sejam interpretados com cautela, reconhecendo que variações na ADM podem ser detectadas na avaliação do estado do paciente e da eficácia do tratamento.

A precisão das medições do ângulo de carga do cotovelo na goniometria foram um pouco maior que a fotogrametria. A variância dos dados pode ser resultado de aberrações ópticas (por exemplo, a paralaxe durante a fotografia ou avaliação com goniômetro). Em algumas situações clínicas em que se necessite avaliar ou documentar pequenas alterações da ADM, a fotogrametria pode ser o melhor método (25).

Quando aplicado o teste $t$ de Student, entre os grupos de examinadores, para determinar a correlação intraexaminadores no ângulo de carga do cotovelo, foi observada uma correlação positiva nas quantificações angulares. Isso provavelmente porque, para tornar as quantificações angulares mais confiáveis, 
os examinadores usaram posições e pontos de referência anatômicos consistentes, com os quais alinharam os braços e o eixo do goniômetro e o traçar das duas semirretas no software ImageJ (Gráfico 3).

\section{Ângulo Q do joelho}

O corpo do fêmur curva-se ligeiramente medialmente à medida que desce em direção ao joelho. Essa orientação oblíqua se dá em razão do ângulo de 125 graus natural de inclinação da parte proximal do fêmur. Como a face articular da parte proximal da tíbia está orientada quase horizontalmente, o joelho forma um ângulo, com seu lado lateral, de aproximadamente 170 a 175 graus (22).

0 ângulo Q é formado pela intersecção das linhas traçadas a partir da espinha ilíaca ântero-superior (EIAS) e da tuberosidade da tíbia por meio do ponto médio da patela $(25,28)$. Nos homens, esse ângulo é de 13 graus e nas mulheres, de 18 graus. Esse ângulo é importante na prática clínica, pois a alteração dos valores de referência para homens e mulheres pode estar associada a patologias, tais como condromalácia patelar ou subluxação patelar.

No estudo de Tomish et al. (29), o nível de confiabilidade encontrado para a mensuração do alinhamento patelofemoral (ângulo Q), com 27 indivíduos assintomáticos, foi de média a boa intraexaminador $(0,63)$ e fraca $(0,23)$ interexaminador.

Greene et al. (30) investigaram, por meio do coeficiente de correlação intraclasse (ICC), a confiabilidade intra e interexaminador da mensuração do ângulo Q comparado com medidas desse ângulo em imagens radiográficas. Para as medições interexaminador, os ICCs oscilaram entre $0,17-0,29$, enquanto para as medidas intra, os CCIs oscilaram entre 0,14-0,37. A média do ICC entre a mensuração in vivo e as derivadas das radiografias variaram entre 0,13-0,32. Esse estudo, portanto, demonstra um nível de confiabilidade pobre inter e intraexaminador e fraca correlação entre a avaliação in vivo e a análise radiográfica do ângulo $\mathrm{Q}$.

Entretanto, encontrar um erro padrão na avaliação do ângulo Q tem uma decisão clínica importante. Piva et al. (31) observaram que um erro em 2,4 graus equivaleria a aumentar ou diminuir a força lateral do quadríceps em 2,9 kg em um indivíduo em que o quadríceps gera uma força de $68 \mathrm{~kg} / \mathrm{f}$. Por essa razão, alternativas para o uso de uma goniometria padronizada devem ser levadas em consideração.

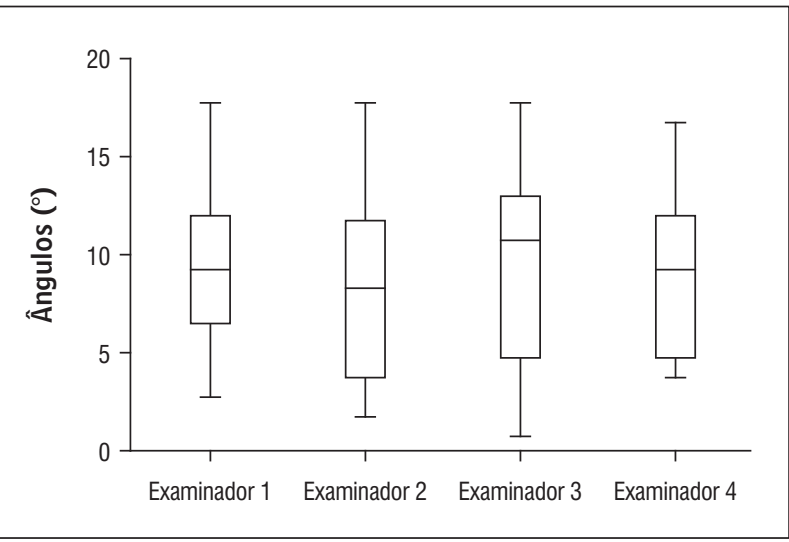

Gráfico 1 - Correlação interexaminadores na mensuração do ângulo de carga do cotovelo pelo método fotogrametria

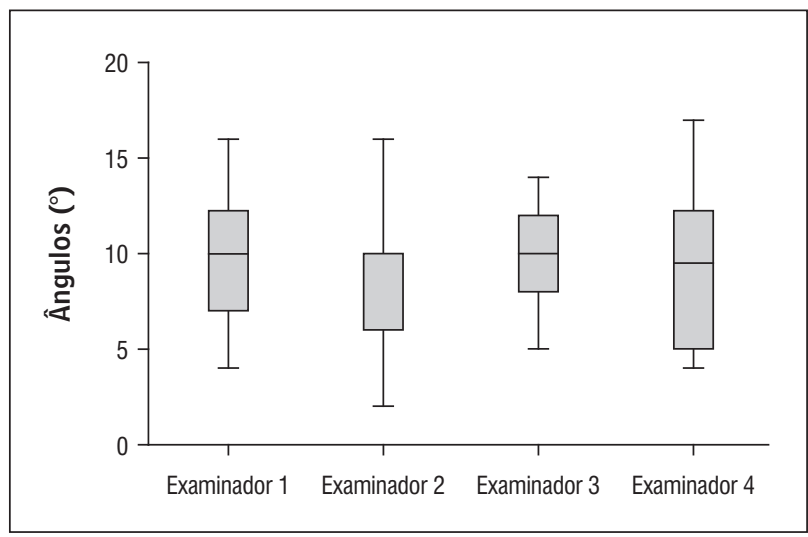

Gráfico 2 - Correlação interexaminadores na mensuração do ângulo de carga do cotovelo pelo método goniometria

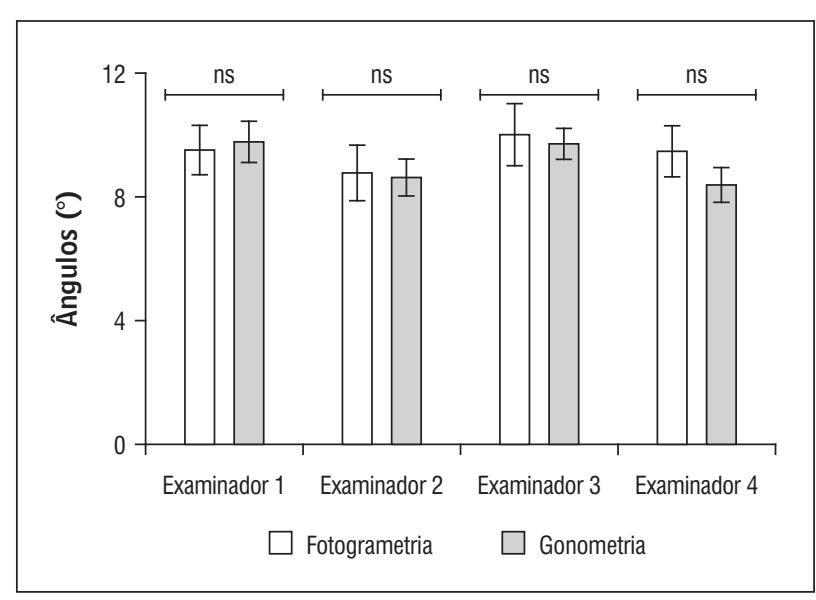

Gráfico 3 - Correlação intraexaminadores na mensuração do ângulo de carga do cotovelo pelo método fotogrametria versus goniometria

Legenda: *ns $=$ não significativo (nível de significância de alfa $<0,05)$. 
Os dados aqui apresentados (Gráficos 4, 5 e 6) mostram alta correlação interexaminador para avaliação fotogramétrica $(\mathrm{p}=0,8396)$ e baixa correlação na mensuração clínica com o goniômetro ( $\mathrm{p}=$ $0,0114)$. Esses dados corroboram com os estudos de Greene et al. (29), que encontraram uma confiabilidade intra e interexaminadores baixa para a medida clínica desse ângulo.

Por outro lado, Caylor, Fites e Worrel (32) encontraram resultados de ICC acima de 0,80 para a confiabilidade intra-examinador e acima de 0,60 para a confiabilidade interexaminador para a medida do ângulo Q.

Acredita-se que a ICC baixa na correlação intraexaminador e interexaminador por goniometria, possivelmente, pelos pontos anatômicos de referência serem distantes entre si e dispostos de maneira que a conformação dos segmentos - inclusive em virtude da massa muscular - atrapalha o posicionamento dos braços do goniômetro. A medida do ângulo $Q$ envolve posturas de mais de um complexo articular, dentre os quais se destacam a pelve, o quadril, o fêmuro-patelar e o fêmuro-tibial, somando entre si quase uma dezena de graus de liberdade (33). Dessa forma, alterações posturais em cada um dos graus de liberdade desses três complexos articulares (pelve, quadril e joelho) podem alterar a medida do ângulo $\mathrm{Q}$ tanto na goniometria quanto na fotogrametria.

\section{Ângulo do Joelho}

O alinhamento do joelho (ou seja, o ângulo formado pela intersecção do quadril, joelho, tornozelo), é um fator determinante da distribuição da carga. Em teoria, qualquer mudança a partir de um alinhamento neutro ou colinear do quadril, joelho e tornozelo afetará a distribuição de carga no joelho (34).

A execução da marcha também pode ser afetada por alteração desse ângulo. Se um indivíduo apresenta, por exemplo, um genu recurvatum, ele transferirá o peso do corpo diretamente a partir do fêmur e tíbia sem o amortecimento e a absorção que uma flexão do joelho proporciona durante a fase de contato do calcâneo no solo.

Encontrar um instrumento preciso e confiável para medir a amplitude de movimento da articulação do joelho - medida essa muitas vezes necessária como parte do tratamento - é sempre de interesse de fisioterapeutas. Em nosso estudo foi possível inferir que a

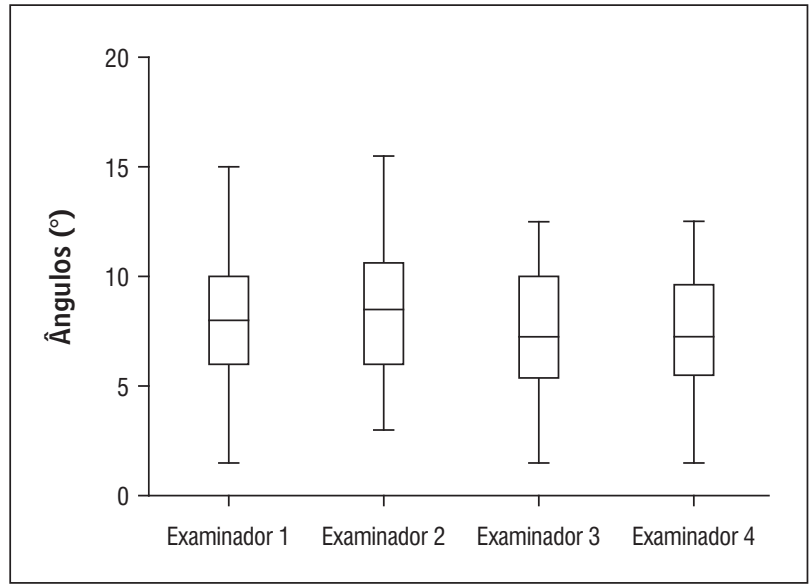

Gráfico 4 - Correlação interexaminadores na mensuração do ângulo $Q$ do joelho pelo método fotogrametria

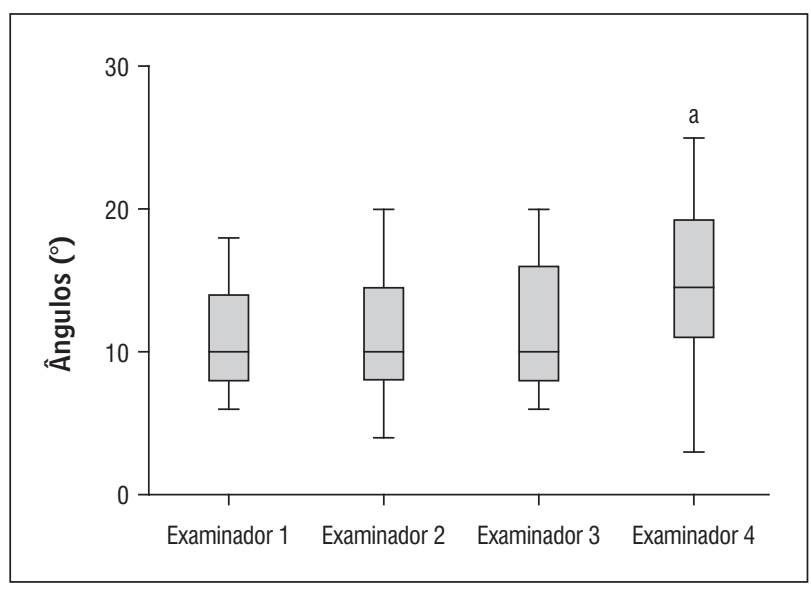

Gráfico 5 - Correlação interexaminadores na mensuração do ângulo $Q$ do joelho pelo método goniometria

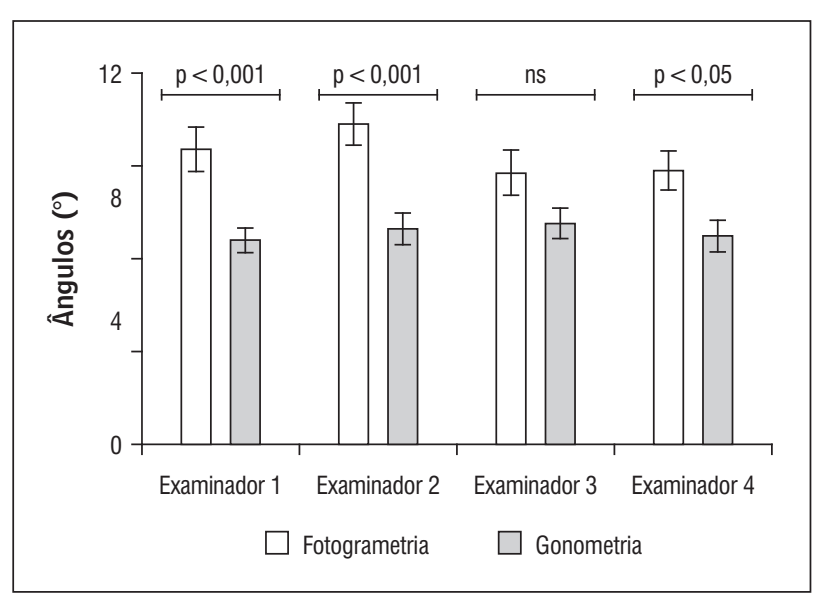

Gráfico 6 - Correlação intraexaminadores na mensuração do ângulo $Q$ do joelho pelo método fotogrametria versus goniometria

Legenda: *ns = não significativo (nível de significância de alfa $<0,05)$. 
mensuração do ângulo de flexão/extensão do joelho (ângulo do joelho), realizada pelos dois diferentes métodos de avaliação, apresentou confiabilidade variada tanto intra como interexaminadores (Tabela 1).

A partir do resultado de nossos testes de confiabilidade, discordamos da aceitação do método de avaliação por goniometria, proposto em alguns estudos $(4,5)$, como aceitável para a quantificação angular do joelho. Em nosso estudo foi possível verificar que houve diferença estatisticamente significante nos valores encontrados interexaminadores na quantificação angular por goniometria $(\mathrm{p}=0,0233)$ (Gráficos 7 e 8).

Da mesma forma, na correlação intraexaminador foi possível observar diferenças significativas nas estimativas angulares determinadas pelos examinadores 1 e 3 ( $p<0,01$ e $p<0,05$, respectivamente) (Gráfico 9).

Várias fontes potenciais de dificuldade, tais como medir o paciente em várias posturas, erros no manuseio do instrumento, nível de cooperação do paciente ou habilidade do examinador, podem fazer com que seja mais difícil obter um valor angular equivalente comparando-se a outro método de avaliação angular. No entanto, neste estudo ainda foi possível obter entre os examinadores (por fotogrametria) medidas confiáveis $(\mathrm{p}=0,1255)$.

\section{Ângulo tibiotársico do tornozelo}

Um indivíduo com músculos posteriores pouco encurtados apresentará o ângulo coxofemoral e tibiotársico do tornozelo de aproximadamente $90^{\circ}$, ficando a coluna quase na horizontal durante a inclinação do tronco para frente. Esse ângulo é obtido baseando-se nos pontos anatômicos cabeça da fíbula e maléolo lateral, marcados com etiquetas adesivas $(35,36)$. 0 eixo horizontal baseia-se na direção do $\mathrm{V}$ metatarso, paralelo ao eixo horizontal. Considera-se como ângulo normal o valor de $90^{\circ}$, ATT aberto quando a medida obtida foi maior que $90^{\circ}$, e ATT fechado para ângulos menores que $90^{\circ}$.

A Tabela 1 apresenta os valores da média \pm desvio-padrão da média e aplicação da análise de variância (ANOVA one-way), seguidos por teste post-hoc (Newman-Keuls) para comparação dos examinadores no exame do ângulo tibiotársico do tornozelo. Podese observar que o ângulo tibiotársico apresentou boa reprodutibilidade na avaliação por biofotogrametria

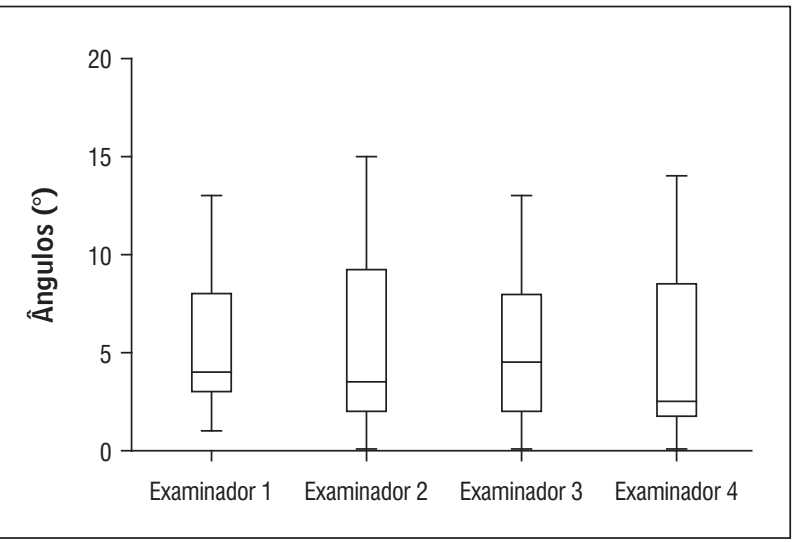

Gráfico 7 - Correlação interexaminadores na mensuração do ângulo de flexão/extensão do joelho pelo método fotogrametria

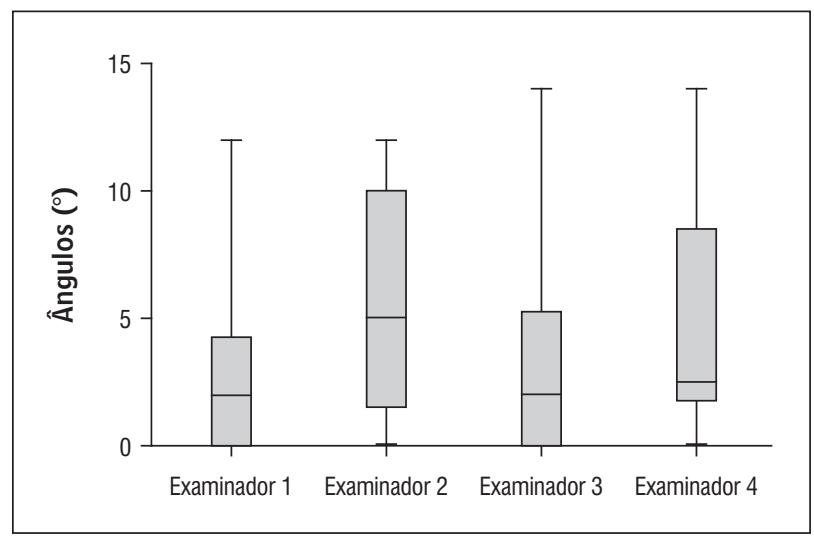

Gráfico 8 - Correlação interexaminadores na mensuração do ângulo de flexão/extensão do joelho pelo método goniometria

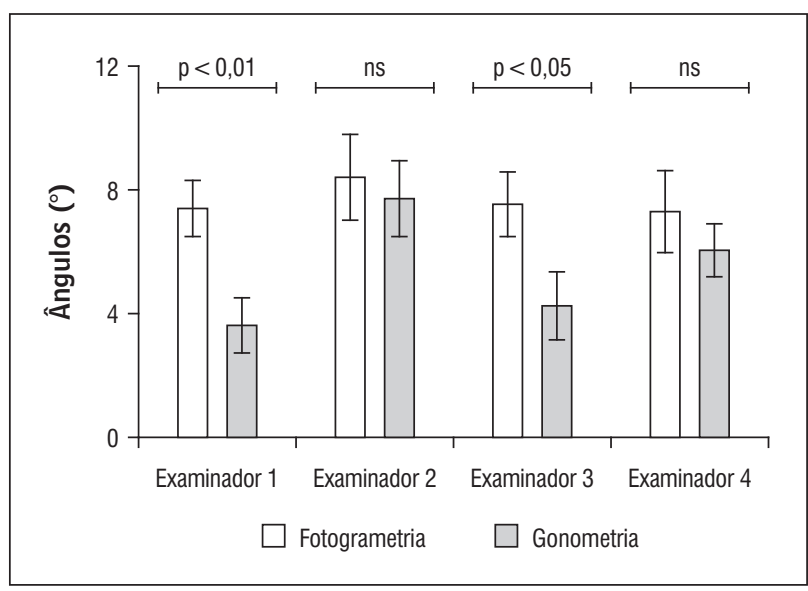

Gráfico 9 - Correlação intraexaminadores na mensuração do ângulo de flexão/extensão do joelho pelo método fotogrametria versus goniometria

Legenda: *ns = não significativo (nível de significância de alfa $<0,05)$. 
$(p=0,5660)$ (Gráficos 10 e 11), corroborando com um estudo de Carregaro, Silva e Gil Coury (37) com 35 indivíduos sadios do gênero masculino, não sedentários e que tiveram os seus músculos posteriores da coxa analisados, de acordo com várias medidas angulares, por fotogrametria (entre elas o ângulo tibiotársico - ICC $=0.96$ ).

0 mesmo estudo afirma que todos os ângulos analisados apresentaram ótima reprodutibilidade intra-avaliadores (ICC $=0,98$ ) (37). Contudo, em nosso estudo foi observado que houve diferenças estatisticamente significativas entre os examinadores na avaliação com o goniômetro ( $\mathrm{p}<0,0001)$ e que nas avaliações intraexaminadores houve diferenças, principalmente, entre os examinadores 1 e 2 (Gráfico 12).

Os menores valores de confiabilidade, obtidos por meio da goniometria em relação à fotogrametria, podem ser atribuídos a diferenças no manuseio dos instrumentos de avaliação. Na goniometria, deve-se considerar a dificuldade de localização dos pontos de referência anatômicos, principalmente a cabeça da fíbula. Outro aspecto está relacionado à possibilidade de não fixação do goniômetro sobre o corpo do indivíduo (38); isso pode ocasionar pequenas oscilações no posicionamento do goniômetro, prejudicando os níveis de reprodutibilidade da medida.

Além dos possíveis erros relacionados ao manuseio dos equipamentos, existe ainda o erro introduzido pelo examinador que precisa localizar visualmente a estrutura anatômica que será utilizada como referência para determinação da posição dos braços do equipamento.

0 procedimento de análise fotogramétrica demonstrou ser prático e útil. No entanto, apesar de a confiabilidade ter sido estabelecida, os achados devem ser vistos com cautela, pois a aplicação desse método em associação com marcadores ósseos superficiais pode estar permeada por erros de medida em razão do movimento dos marcadores na pele (39).

\section{Considerações finais}

É essencial que fisioterapeutas e outros profissionais que precisam determinar valores angulares considerem níveis de confiabilidade dos instrumentos usados para quantificação da ADM no contexto de sua prática própria.

Os menores valores de confiabilidade, obtidos por meio da goniometria em relação à fotogrametria,

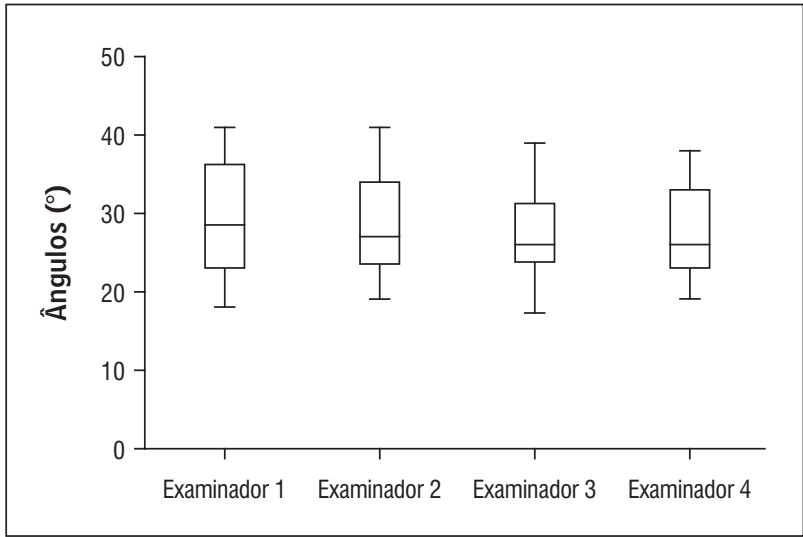

Gráfico 10 - Correlação interexaminadores na mensuração do ângulo tibiotársico do tornozelo pelo método fotogrametria

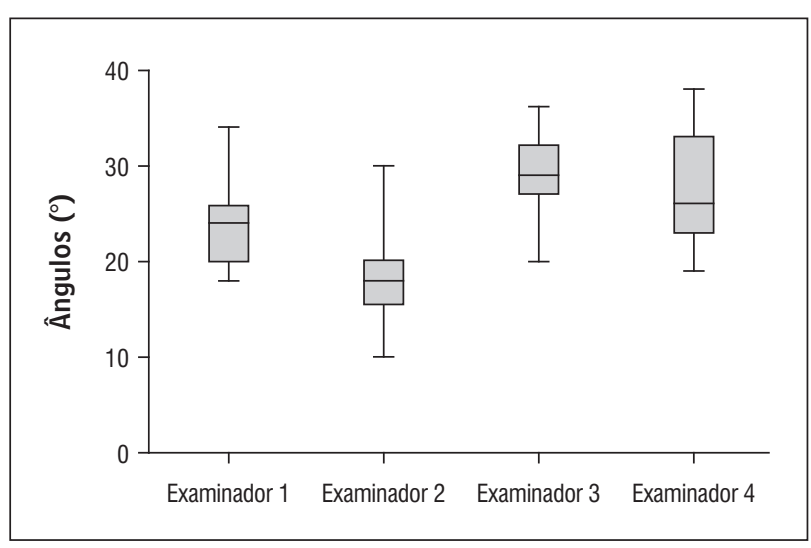

Gráfico 11 - Correlação interexaminadores na mensuração do ângulo tibiotársico do tornozelo pelo método goniometria

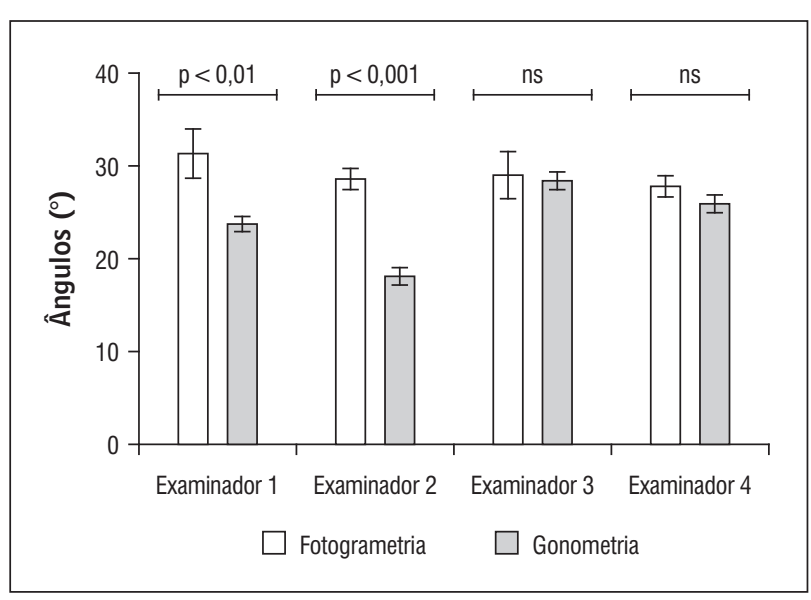

Gráfico 12 - Correlação intraexaminadores na mensuração do ângulo tibiotársico do tornozelo pelo método fotogrametria versus goniometria

Legenda: *ns $=$ não significativo (nível de significância de alfa $<0,05)$. 
podem ser atribuídos a diferenças no manuseio do equipamento. 0 goniômetro é um instrumento confiável na maioria das evidências, porém, a confiabilidade das medições depende principalmente da uniformização dos procedimentos.

Considerações metodológicas relativas ao estabelecimento de confiabilidade e padronização da colocação dos marcadores se fazem necessárias, de modo a oferecer opções de avaliação ainda mais confiáveis para a prática clínica. No entanto, esses resultados também devem ser aceitos com cautela, já que artefatos de movimentação da pele podem ocorrer principalmente em marcadores colocados em regiões que servirão como fulcro do movimento ou áreas em que haverá mobilidade durante o posicionamento do indivíduo para a foto, como, por exemplo, a região do trocânter maior do fêmur.

Se a aplicação de diferentes testes na mensuração do mesmo parâmetro levar a resultados comparáveis e consistentes, pode-se garantir o incremento da qualidade da comunicação entre diferentes profissionais e contribuir para o embasamento científico da prática clínica.

Além disso, esperamos que os profissionais de saúde que trabalham com quantificação angular sejam estimulados a continuar a desenvolver a aplicação clínica da fotointerpretação. Ambos os instrumentos são confiáveis e aceitáveis, porém, mais evidências ainda são necessárias para suportar a utilização desses instrumentos, pois poucos pesquisadores têm utilizado o mesmo desenho de estudo, e a comparação dos resultados entre eles, muitas vezes, são difíceis.

\section{Referências}

1. Sackett DL. Medicina baseada em evidências: prática e ensino. 2a ed. Porto Alegre: Artmed; 2003.

2. Kassirer JP. Our stubborn quest for diagnostic certainty: a cause of excessive testing. N Eng J Med. 1989; 320(22):1489-91.

3. Palmer ML. Fundamentos das técnicas de avaliação musculoesquelética. 2a ed. Rio de Janeiro: Guanabara Koogan; 2000.

4. Braz RG, Castilo Goes FPD, Carvalho GA. Confiabilidade e validade de medidas angulares por meio do software para avaliação postural. Fisioter Mov. 2008; 21(3):117-26.
5. Venturini C, Ituassú NT, Teixeira LM, Deus CVO. Confiabilidade intra e interexaminadores de dois métodos de medida da amplitude ativa de dorsiflexão do tornozelo em indivíduos saudáveis. Rev Bras Fisioter. 2006;10(4):407-411.

6. Gogia PP, Braatz JH, Rose SJ, Norton BJ. Reliability and validity of goniometric measurements at the knee. Phys Ther. 1987;67(2):192-5.

7. Gerhardt JJ, Rondinelli RD. Goniometric techniques for range-of-motion assessment. Phys Med Rehabil Clin N Am. 2001;12(3):507-27.

8. Yaikwawongs N, Limpaphayom N, Wilairatana V. Reliability of digital compass goniometer in knee joint range of motion measurement. J Med Assoc Thai. 2009;92(4):517-22.

9. Norkin CC, White DJ. Medida da amplitude de movimento articular: um guia para goniometria. Philadelphia: FA Davies Co; 1995.

10. Kisner C, Colby LA. Exercícios terapêuticos: fundamentos e técnicas. 3a ed. São Paulo: Manole; 1998.

11. Davies, GJ. A compendium of isokinetics in clinical usage and rehabilitation techniques. 4a ed. Onalaska: WIS \& S Publishers; 1992.

12. Vieira ER, Gil CHJC. Interface entre eletrogoniômetro e indivíduo: comparação entre as fixações com e sem canaletas de acoplamento. Rev Bras Fisioter. 2002;6(2):77-85.

13. Barauna M, Ricieri DV. Biofotogrametria. Revista 0 COFFITO. 2002;17:7-11.

14. Venturini C, André A, Aguilar BP, Giacomelli B. Confiabilidade de dois métodos de avaliação da amplitude de movimento ativa de dorsiflexão do tornozelo em indivíduos saudáveis. Acta Fisiatr. 2006;13(1):41-5.

15. Magazoni VS. Estudo correlacional entre a expansibilidade da caixa torácica e a capacidade vital pulmonar nos indivíduos portadores e não portadores de espondilite anquilosante [dissertação]. Uberlândia: Centro Universitário do Triângulo; 2000.

16. Amado-João SM. Métodos de avaliação clínica e funcional em fisioterapia. Rio de Janeiro: Guanabara Koogan; 2006.

17. Andrade JA, Leite VM, Teixeira-Salmela LF, de Araújo PMP, Juliano Y. Estudo comparativo entre os métodos de estimativa visual e goniometria para avaliação das amplitudes de movimento da articulação do ombro. Acta Fisiatr. 2003;10(1):12-6. 
18. Iunes DH, Castro FA, Salgado HS. Confiabilidade intra e interexaminadores e repetibilidade da avaliação postural pela fotogrametria, 2005. [acesso em 18 jul. 2010]. Disponível em: http://www.crefito3.com.br/ revista/rbf/rbfv9n3/pdf/327_334_fotogrametria.pdf

19. Van Maanen CJ, Zonnenberg AJ, Elvers JW, Oostendorp RA. Intra/interrater reliability of measurements on body posture photographs. Cranio. 1996;14(4):326-31.

20. Braun BL, Amundson LR. Quantitative assessment of head and shoulder posture. Arch Med Phys Rehabil. 1989;70(4):322-9.

21. Sanches HM, Barreto RR, Baraúna MA, Canto RST, Morais EG. Avaliação postural de indivíduos portadores de deficiência visual através da biofotogrametria computadorizada. Fisioter Mov. 2008;21(2):11-20.

22. Neumann DA. Cinesiologia do aparelho musculoesquelético: fundamentos para a reabilitação física. Rio de Janeiro: Guanabara Koogan; 2006.

23. Nordin M, Frankel VH. Biomecânica básica do sistema musculoesquelético. Rio de Janeiro: Guanabara Koogan; 2003.

24. Goktepe A, Emre Ak, Söğüt M, Karabörk H, Feza Korkusuz MD. Joint angles during successful and unsuccessful tennis serves kinematics of tennis serve. Joint Diseases and Related Surgery. 2009;20(3):156-60.

25. Cleland J. Netter - exame clínico ortopédico: uma abordagem baseada em evidências. Rio de Janeiro: Elsevier; 2006.

26. Armstrong AD, MacDermid JC, Chinchalkar S, Stevens RS, King GJ. Reliability of range-of-motion measurement in the elbow. J Shoulder Elbow Surg. 1998;7(6): 573-80.

27. Flowers KR, Stephens-Chisar J, LaStayo P, Galante BL. Intrarater reliability of a new method and instrumentation for measuring passive supination and pronation. J Hand Ther. 2001;14(1):30-5.

28. Sacco ICN, Tanaka C. Cinesiologia e biomecânica dos complexos articulares. Rio Janeiro: Guanabara Koogan; 2008.

29. Tomsich DA, Nitz AJ, Threlkeld AJ, Shapiro R. Patellofemoral alignment: reliability. J Orthop Phys Ther. 1996;23(3):200-8.
30. Greene CC, Edwards TB, Wade MR, Carson EW. Reliability of the quadriceps angle measurement. Am J Knee Surg. 2001;14(2):97-103.

31. Piva SR, Fitzgerald K, Irrgang JJ, Jones S, Hando BR, Browder DA, et al. Reliability of measures of impairments associated with patellofemoral pain syndrome. BMC Musculoskelet Disord. 2006;7:33.

32. Caylor D, Fites R, Worrel TW. The relationship between quadriceps angle and anterior knee pain syndrome. J Orthop Sports Phys Ther. 1993;17(1):11-6.

33. Sacco ICN, Alibert S, Queiroz BWC, Pripas D, Kieling I, Kimura AA, et al. Confiabilidade da fotogrametria em relação à goniometria para avaliação postural de membros inferiores. Rev Bras Fisioter. 2007;11(5):411-7.

34. Sharma L, Song J, Felson DT, Cahue S, Shamiyeh E, Dunlop DD. The role of knee alignment in disease progression and functional decline in knee osteoarthritis. JAMA. 2001;286(2):188-95.

35. Marques AP. Manual de goniometria. 2a ed. São Paulo: Manole; 2003.

36. Kendall E. Músculos provas e funções. 4a ed. São Paulo: Manole; 2007.

37. Carregaro RL, Silva LCCB, Gil Coury HJC. Comparação entre dois testes de flexibilidade dos isquiotibiais. Rev Bras Fisioter. 2007;11(2):139-45.

38. Chaves TC, Nagamine HM, Belli JFC, de Hannai MCT, Bevilaqua-Grossi D, de Oliveira AS. Confiabilidade da fleximetria e goniometria na avaliação da amplitude de movimento cervical em crianças. Rev Bras Fisioter. 2008;12(4):283-9.

39. Stagni R, Fantozzi S, Cappello A, Leardini A. Quantification of soft tissue artifact in motion analysis by combining 3D fluoroscopy and stereophotogrammetry: a study on two subjects. Clin Biomech. 2005; 20(3):320-9.
Recebido:15/09/2010

Received: 09/15/2010

Aprovado: $15 / 03 / 2011$

Approved: 03/15/2011 